\title{
The Feasibility Analysis about Electrical Appliance Enterprises to Enter the Plastics Recycling Industry
}

\author{
Tao Wang \\ Southwest University of Science and Technology \\ Email:1060822779@qq.com
}

\begin{abstract}
When the fastigium of the waste electrical appliances being scraped comes, and circular economy develops rapidly, household electrical appliances manufacturing enterprises are responsible for waste household appliances processing. This paper mainly describes current situation of the appliance waste plastics recycling industry, and then analyzes from the market and technical operation, finally comes to the conclusion that it's absolutely feasible for the household electrical appliance enterprises to get into plastic recycling industry.
\end{abstract}

Keywords- waste plastic recycling, feasibility, electronic appliances enterprise

\section{INTRODUCTION}

Becoming a big country of electronic appliances manufacturing in the world, waste electronic and electrical appliances are also entering the discard peak. With the rapid development of electronic technology, products are updated faster and faster. It's estimated that a few years later, scrapped and recycled household appliances will increase substantially in China. The TV sets will be about 500 millions, the refrigerator about 400 millions, personal computer about 500 millions and about 2000 millions mobile phone every year. Plastics are important part of the waste electrical and electronic equipments, weighing more than 30$40 \%$ of one product. How to fully recover and utilize the waste plastics to realize resources circulation is undoubtedly an important subject for the household electrical appliance enterprises.

\section{DeVelopment Status OF WASte Plastic RECYCLING INDUSTRY}

\section{A. Current situation of Waste Plastic Recycling Industry Overseas Situation}

The recycling, separation, and regeneration of useless old household appliance plastic is one of the important factors to build the circular economy system. The EU has changed from $80 \%$ of waste plastics landfill method to the vaporization recovery processing method. The United States Association of plastic regulated in plastic products surface to be printed with clear identification, thereby greatly simplifying the recovery of materials, which makes it convenient for material regeneration. Japan established the network of recycling and regeneration enterprises all over the country, covering from consumers, streets to recycling companies and recycling enterprises. The work division is clear. It's the most advanced country of managing system and recycling technology.

\section{B. Domestic Situation}

At present, there are two ways to deal with the waste electrical and electronic products in our country: One is to collect by pick-up traders from streets, or by manufacturers and distributors, then get into the vintage market to sales to the low-end consumers; the second is to dismantle and processing, then extract noble metals. Most of recycling factory mainly dismantle the used electrical appliances and then process them separately, but the technology is at low level, and the automatic degree is low, the product added value is low, environmental pollution is very serious, and real deep processing enterprises are few.

\section{THE MARKET FEASIBILITY ANALYSIS OF ELECTRICAL APPLIANCE ENTERPRISES INTO THE RECYCLING OF WASTE PLASTICS INDUSTRY}

First, the qualification admission system of discarded electronic products processing is clearly and strictly set up in the" waste electrical and electronic products recycling regulations" and" household appliances trade-in implementation measures ( Revised Draft)" executed from January 1, 2011. It's strictly ruled for the place, facilities, methods and qualified personnel. Special funds and subsidies are also set up to promote producer to take some responsibility of processing waste electrical and electronic products, supporting the processing enterprises to realize industrialization. Policy guarantee is provided by national and local government's policy enforcement and follow-up policy.

Secondly, National Development and Reform Commission has decided to carry out extended responsibility system for the discarded electrical products recycling and processing area. For the purpose of resource recycling and environmental protection, set up diversified recycling and centralized processing system of discarded electrical appliances. This is a double-edged sword: not only to bring great pressure to the enterprises, but also make enterprises active to seize the recycling resources, which turns pressure into motive force, laying good foundation for them to enter the waste plastic recycling industry.

Thirdly, most of the current domestic household electrical appliance enterprises have a long history, with advanced scientific corporate culture, strong staff and a 
complete talent bank, in which there are elite of management and technology. This provides the team to enter the industry.

At last, household appliances enterprises have a large number of distributors which establish the recovery channel.

\section{The Technical Feasibility Analysis of}

ELECTRICAL APPLIANCE ENTERPRISES INTO THE RECYCLING OF WASTE PLASTICS INDUSTRY.

The products of household electrical appliance enterprises are concentrated, mainly are TV sets, freezers, washing machines and air conditioners. These products' plastic composition is simple, most is ABS, PS (HIPS), PP etc. (table below).

The key technologies of recycling waste plastics are three: plastic sorting and separation technology; cleaning technology; value appraisal and application direction.

\section{A. Polystyrene(PS) Recovery Method}

1) Physical Recycling Method: physical method to recycle polystyrene foam and waste polystyrene plastic is currently the most commonly used and the most economical method. A typical recovery process is as follows: obvious sundries are wiped off artificially when raw materials passing by conveyor belt, then crush the raw materials and wash it with water mixed with cleaning agent, then enter the vibration sieve to remove cleaning water, then jet it with clean water, some solid sundries and pulp are removed at the same time. After fulling, the materials are sent to centrifugal driers to wipe off surface water. Now there is quite a lot water to be removed in the materials. It can be done by extrusion, heating, or exhausting. It is in common use to exhaust it with vacuum exhauster, cooperated with melt filter. If needed, before granulation, other materials like rubber can be added to change the attribute.

2) Technical Modification:Heat the PS waste plastic to more than $200^{\circ} \mathrm{C}$ to melt and granulate. Polystyrene melt granulation process is simple, including crushing, washing, drying, granulation, and extrusion. Generally, before grainy PS material put into market, it needs further attribute change by double screw melt granulation, and added toughening agent, antioxidant, and compatibilizer.

\section{B. ABS Plastics Recycling Method}

ABS plastic is a kind of modified plastic mixed by three composition, acrylonitrile(A), butadiene (B), and styrene (S). It is the most used engineering plastic at quantity. ABS plays excellent comprehensive performance, good for molding, easy to electroplating. Compared to other engineering plastics, it's cheaper. So it's already widely used in household appliances, automobiles, telecommunications, machinery and other industries. The biggest problem of ABS plastic recycling is the separation of HIPS. ABS and HIPS cannot be mixed together. If blended, it's prone to be brittle, emerge bubble, and stratification. ABS recovery method is mainly physical. The point is to remove impurities like metal, and then add to new materials to make appliances components such as shell. To sum up, household electrical appliance enterprises occupy the recovery channel and are familiar with materials of all product components, so they are in the ascendant at deep processing projects of waste plastics. Technically, during initial stages they can primarily directly granulate, sort, crush (reduce), clean (removal of dirt and oil), melting granulate (devolatilization, and gas removal). They can sell such products as secondary brand. Later, through modification of polymer materials, value of primary product will greatly improve.

\section{SUMMARY}

With improvement of national policies and regulations at waste electrical appliances recycling, the increasing social concern of the environmental protection, it is believed that the recycling of waste electrical appliances industry will get more and more attention. Household electrical appliance enterprises should be keenly aware of this trend, to create greater social benefit as well as their own economic benefit.

\section{REFERENCES}

[1] Waste Electrical and Electronic Products Recycling Management Regulation

[2] Home Appliance Trade-in Implementation Measures ( Revised Version)

[3] Solid Waste Pollution Prevention Law

[4] Chen Yu: Waste Household Appliances Recycling and Utilization Status and Management Countermeasures (pollution prevention and control technologies, 2005)

[5] Zhan Maosheng, Wang Kai: Foreign Waste Plastic Recycling and Utilization Technology development(plastic, 2007)

[6] Liu Ji: Home Appliance Recycling Plastic Recycling

[7] The Internal Data of SiChuan ChangHong Electric Company Limited

[8] China Recycled Plastics Recycling Industry Situation and Development Forecast

TABle I. Four Kinds of Home Appliance AcCording To The Types Of Plastic Composition Ratio (\%)

\begin{tabular}{|l|c|c|c|c|}
\hline & TV & refrigerator & washing machine & air conditioner \\
\hline Polypropylene ( PP ) & 8.9 & 24.7 & 76.5 & 21.2 \\
\hline Polyvinyl chloride ( PVC ) & 3.2 & 7.9 & 5.7 & 10.6 \\
\hline Polystyrene ( PS ) & 84.5 & 26.3 & 6.2 & 31.9 \\
\hline AS & 0 & 0 & 0 & 1.7 \\
\hline ABS & 1.7 & 16.3 & 3.0 & 10.8 \\
\hline ASA & 0 & 0 & 0 & 2.5 \\
\hline Polyester & 0 & 0 & 2.0 & 3.7 \\
\hline
\end{tabular}




\begin{tabular}{|l|c|c|c|c|}
\hline Glass fiber reinforced plastic & 0 & 0 & 0 & 8.4 \\
\hline Polyurethane foam & 0 & 21.4 & 0 & 0 \\
\hline The other & 1.7 & 3.4 & 6.6 & 9.2 \\
\hline total & 100 & 100 & 100 & 100 \\
\hline
\end{tabular}

Data sources:" China recycled plastics recycling industry situation and development forecast" 